Flowfield Measurements

Inside a Boundary-Layer Bleed Slot D. O. Davis, B. P. Willis, W. R. Hingst

Reprinted from

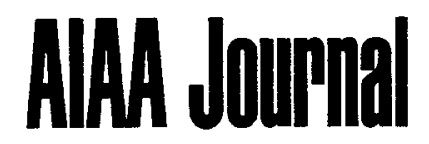

Volume 34, Number 10, Pages 1977-1983

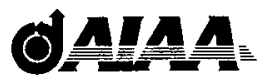

A publication of the

American Institute of Aeronautics and Astronautics, Inc. 1801 Alexander Bell Drive, Suite 500

Reston, VA 22091 


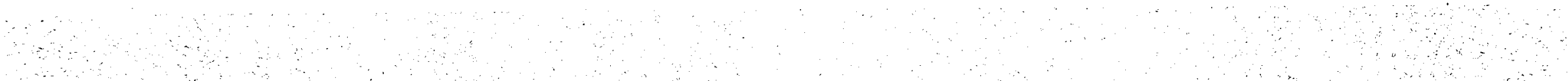




\title{
Flowfield Measurements Inside a Boundary-Layer Bleed Slot
}

\author{
D. O. Davis, ${ }^{*}$ B. P. Willis, ${ }^{\dagger}$ and W. R. Hingst ${ }^{\dagger}$ \\ NASA Lewis Research Center, Cleveland, Ohio 44135
}

\begin{abstract}
An experimental investigation was conducted to determine the flowfield inside a bleed slot used to control an oblique shock-wave and turbulent boundary-layer interaction. The slot was oriented normal to the primary flow direction and had a width of $1.0 \mathrm{~cm}$ (primary flow direction) and a length of $2.54 \mathrm{~cm}$ and spanned $16.5 \mathrm{~cm}$. The approach boundary layer upstream of the interaction was nominally $3.0 \mathrm{~cm}$ thick. Two operating conditions were studied: $M=1.98$ with a shock generator deflection angle of $6 \mathrm{deg}$ and $M=2.46$ with a shock generator deflection angle of $8 \mathrm{deg}$. Measurements include surface and flowfield static pressure, pitot pressure, and total mass flow through the slot. The results show that despite an initially two-dimensional interaction for the zero-bleed-flow case, the slot does not remove mass uniformly in the spanwise direction. Inside the slot, the flow is characterized by two separation regions, which significantly reduce the effective flow area. The upper separation region acts as an aerodynamic throat, resulting in supersonic flow through much of the slot.
\end{abstract}

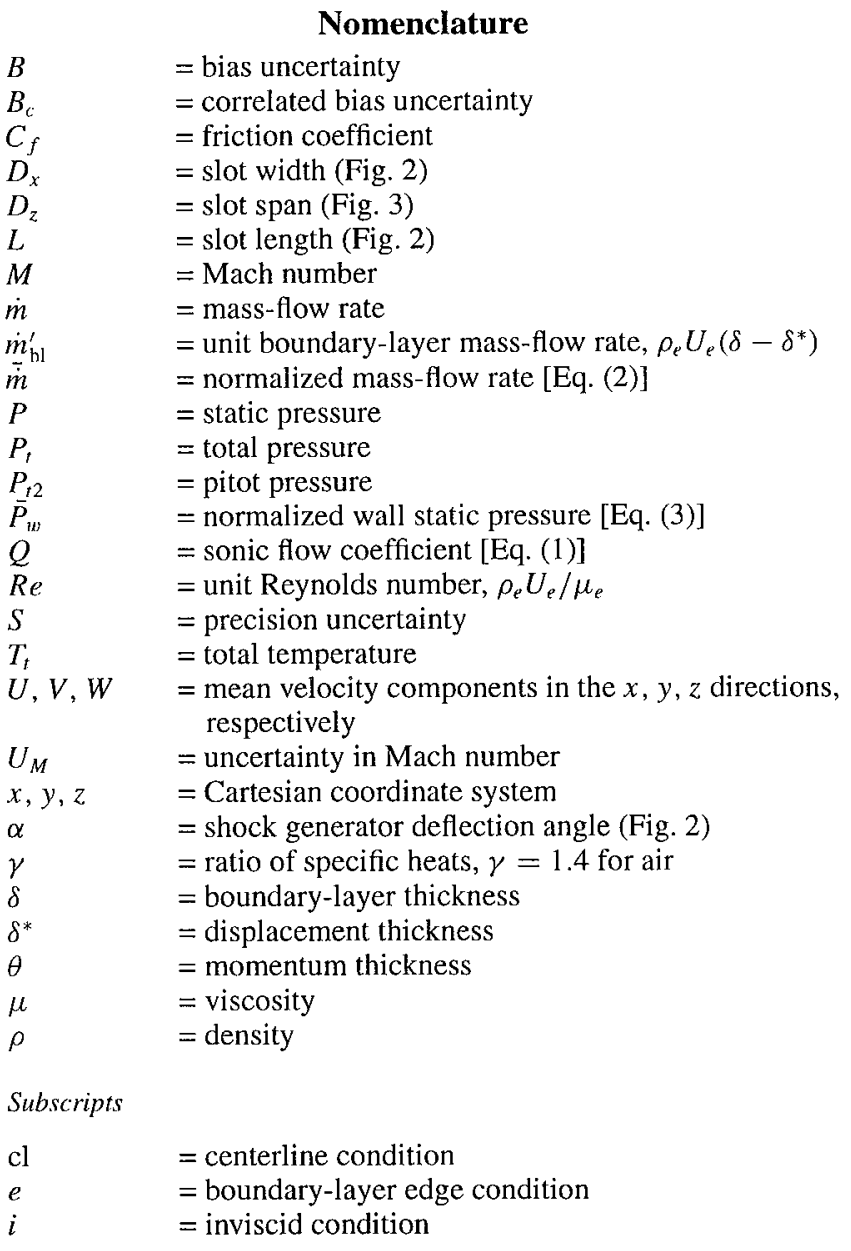

Presented as Paper 95-0032 at the AIAA 33rd Aerospace Sciences Meeting, Reno, NV, Jan. 9-12, 1995; received Sept. 15, 1995; revision received March 16, 1996; accepted for publication April 6, 1996. Copyright (C) 1996 by the American Institute of Aeronautics and Astronautics, Inc. No copyright is asserted in the United States under Title 17, U.S. Code. The U.S. Government has a royalty-free license to exercise all rights under the copyright claimed herein for Governmental purposes. All other rights are reserved by the copyright owner.

*Aerospace Engineer, Inlet, Duct, and Nozzle Flow Physics Branch, Internal Fluid Mechanics Division, 21000 Brookpark Road, M/S 5-11. Senior Member AIAA.

${ }^{\dagger}$ Aerospace Engineer, Inlet, Duct, and Nozzle Flow Physics Branch, Internal Fluid Mechanics Division, 21000 Brookpark Road, M/S 5-11. Member AIAA.

\author{
plen $\quad=$ condition in bleed plenum \\ ref $\quad=$ condition in upstream reference plane \\ $w \quad=$ condition at wall \\ $0=$ condition in wind-tunnel plenum \\ $1,2,3=$ conditions in zones 1,2 , and 3 , respectively (Fig. 2)
}

\section{Introduction}

$\mathbf{P}$ REVENTION or control of boundary-layer separation resulting from a shock-wave and boundary-layer interaction can be achieved by removing low momentum fluid (boundary-layer mass) near the surface through a porous region. ${ }^{1,2}$ The porous region may be a series of discrete perforations (holes) or a single slot. Numerical analysis of the interaction region can be very costly in terms of computer time and grid generation if the flow through the individual holes or the slot is endeavored. This is especially true if the interaction is part of a full supersonic inlet calculation. To avoid this, a global bleed model is sought that eliminates the need for resolving the bleed-flow passages. An effective global bleed model should do two things: predict the amount of mass removed from the boundary layer and predict the condition of the boundary layer downstream of the interaction. The former is important from the standpoint of bleed drag and bleed system scaling, whereas the latter is an indication of the effectiveness of the bleed in maintaining a healthy boundary layer. To achieve these goals, the local flow phenomena in the interaction region, including the bleed passages and bleed plenum, must be understood and accounted for in a model. Not surprisingly, previous investigations resolving the flow through bleed passages have been computational in nature. Hamed et al. studied the oblique shock-wave and laminar boundary-layer interaction with bleed through normal slots ${ }^{3}$ and the oblique shock-wave and turbulent boundary-layer interaction with bleed through various normal ${ }^{4-6}$ and slanted ${ }^{5,7}$ slots. Because the slot configuration is two dimensional, Hamed et al. were able to perform a fairly comprehensive parametric study, including the effects of bleed mass-flow rates, slot location relative to shock impingement location, slot inclination angle, and slot length-to-width ratio. Hahn et al. ${ }^{8}$ also numerically studied the oblique shock-wave and turbulent boundary-layer interaction with bleed through normal slots and, in addition to investigating various shock impingement locations and slot length-to-width ratios, included the effects of two slots with various streamwise spacing. Other researchers ${ }^{9-12}$ considered the more complex (threedimensional) case of oblique shock-wave and turbulent boundarylayer interactions with bleed through holes. These numerical studies identified several important features of the bleed interaction. Among them are the presence of separation region(s) in the bleed passage, which have a large effect on the flow coefficient of the hole or slot, ${ }^{13}$ and the presence of a two-segment barrier shock (see Fig. 1), which may or may not be attached, depending on local flow conditions. Although these studies provide a significant increase in the 


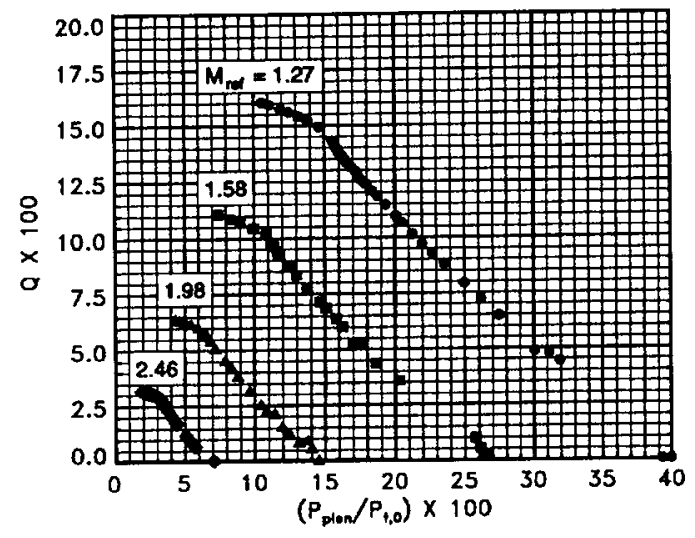

Fig. 6 Sonic-flow coefficient distributions, $\alpha=0$.

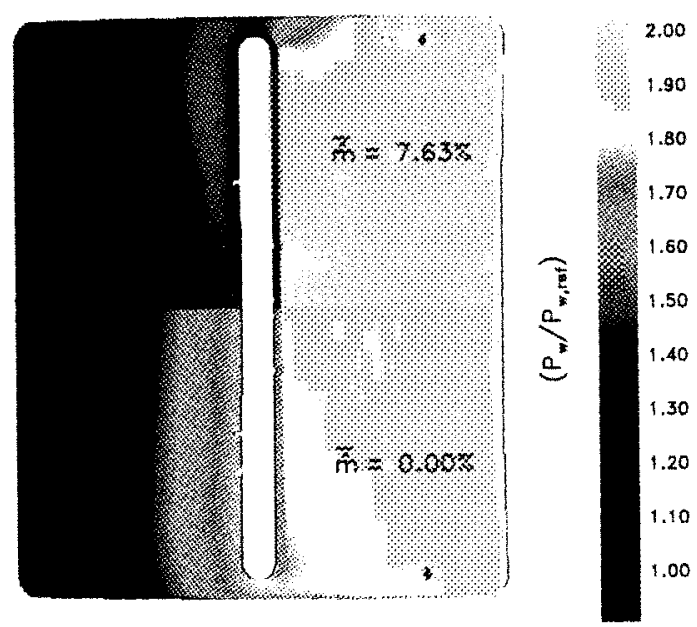

Fig. 7 Surface static pressure from pressure-sensitive paint, case M198A6.

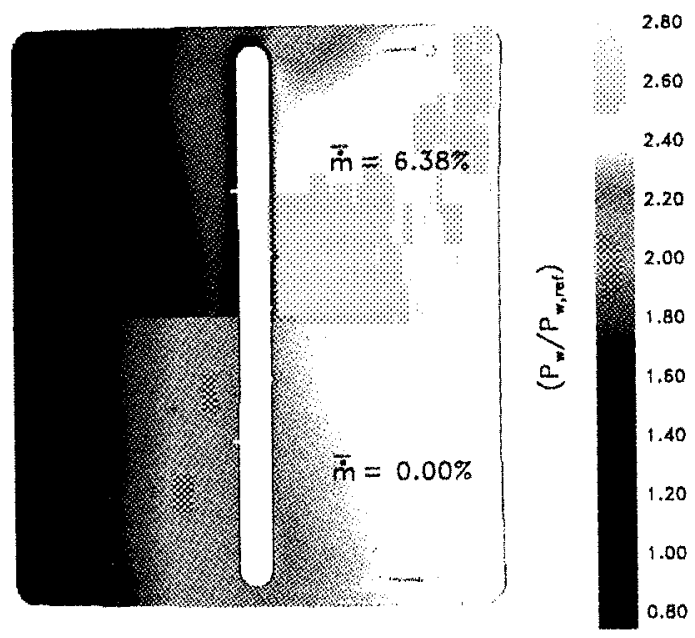

Fig. 8 Surface static pressure from pressure-sensitive paint, case M246A8.

the no-bleed case and the upper half corresponds to the highest bleed flow rate attainable with the bleed system. The bleed rates are given as a percentage of the mass flow in the approach boundary-layer defined as

$$
\overline{\dot{m}}=\frac{100 \cdot \dot{m}}{\left(D_{z}\right) \cdot\left(\dot{m}_{\mathrm{bl}, \text { ref }}^{\prime}\right)}
$$

where $\dot{m}_{\mathrm{bl}, \text { ref }}^{\prime}$ is the unit boundary-layer mass flow in the upstream reference plane (see Table 1 ) and $D_{z}$ is the spanwise dimension of the slot (see Fig. 3). Although the data for each flow rate are shown for only half of the bleed plate, results were obtained across the entire plate and exhibited a high degree of symmetry about the wind-tunnel centerline $(z=0)$.

For the cases with no bleed flow (the lower half of Figs. 7 and 8), the results indicate a reasonably two-dimensional flowfield except in the vicinity of the slot ends. As the bleed flow rate is increased, the upstream influence of the shock wave decreases, but not uniformly across the span of the slot. At the center of the slot $(z=0)$, the upstream influence is significantly less than at the slot ends. This spanwise variation of upstream influence indicates that more mass flow is removed near the center of the slot. Although the interaction is not two-dimensional, the results were observed to be symmetric about the wind-tunnel centerline ( $z=0$ plane) and are still valid for a three-dimensional CFD validation case.

Conventional surface static taps were located axially on the windtunnel centerline through the interaction region. Normalized surface static-pressure distributions along the $x$ axis (centerline) for three bleed rates are shown in Fig. 9 for the M246A 8 case. The normalized wall pressure is defined as

$$
\bar{P}_{u,}=\frac{\left(P_{w}-P_{1, i}\right)}{\left(P_{3, i}-P_{1, i}\right)}
$$

where $i$ denotes the inviscid no-bleed condition. In this plot, the symbols represent data from the conventional surface pressure taps and the solid lines represent data deduced from the pressure-sensitive paint. The theoretical inviscid distribution for the no-bleed case is also represented in this plot. The layout sketch at the top of Fig. 9 shows the inviscid no bleed wave structure. The three bleed rates shown represent the no-bleed case, the maximum bleed attainable for the configuration, and an arbitrary bleed rate between the two extremes.

From Fig. 9 and the corresponding figure for the M198A6 case (shown elsewhere ${ }^{19}$ ), the following observations can be made:

1) The upstream influence of the shock-wave and boundary-layer interaction is reduced by approximately $1.5 \mathrm{~cm}$ for the M198A6 case and by approximately $2.5 \mathrm{~cm}$ for the M246A 8 case when bleed is applied.

2) For both cases, there is very little difference between the distributions corresponding to the two nonzero-bleed rates.

3) For the nonzero-bleed cases, the pressure overshoots the inviscid pressure distribution. This overshoot in pressure is attributed to the barrier shock (see Fig. 1) and, as expected, is greater for the higher-bleed-rate case.

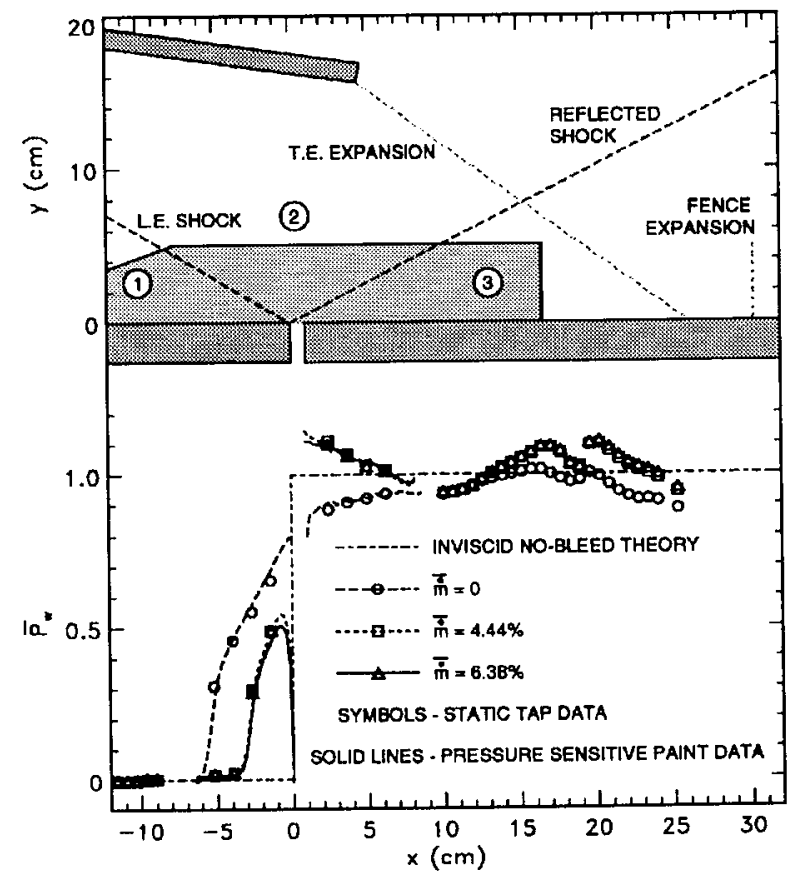

Fig. 9 Normalized surface static-pressure distributions along the $x$ axis, case M246A8. 
4) The pressure-sensitive paint data agree quite well with the conventional static tap data.

5) The drop in pressure below the inviscid value is attributable to the upstream influence of the expansion-wave system set up by the experimental hardware (shock generator and fences).

\section{Flowfield Measurements in the Slot}

For the flowfield measurements, only one bleed rate was considered for each of the two operating conditions. The bleed rate considered corresponds to the maximum attainable with the bleed system and is the same as the highest bleed rate condition reported for the surface static-pressure data. With reference to the sonicflow-coefficient distributions (Fig. 6), for all local Mach numbers, the highest flow rate attainable with the bleed system is always to the left of the aforementioned choke point in the flow coefficient curves.

The knife-edged static probe was used to measure the static pressure in the slot. In Fig. 10, the normalized static pressure along the $x$ axis (top of the slot) is plotted along with the surface static pressure upstream and downstream of the slot for the M246A8 case. From this figure, it is clear that the pressure distribution across the top of the slot is not uniform and follows the trends of the surface static pressure. The slot static-pressure distribution in the plane of symmetry, normalized by the wind-tunnel total pressure $\left(P_{t, 0}\right)$, is shown in Fig. 11 for the M246A8 case. A total of 210 points was measured on a regular grid with $x$ and $y$ spacing as indicated by the tick marks shown in Fig. 11. For presentation purposes, the data have been extrapolated to the slot surfaces by setting the pressure at the surface equal to the flowfield pressure at the first point away from the surface. The normalized bleed plenum static pressure is indicated on the bottom of the figure. Although undoubtedly smeared by the presence of the boundary-layer developing on the knife-edged static probe, the presence of the interior segment of the barrier shock is clearly seen by the large pressure gradient (increase) in the upperright region of the flowfield. It is not clear, however, whether the shock is attached or not. Outside this region, the static pressure is fairly uniform throughout the slot.

A $0.508-\mathrm{mm}$-diam pitot probe was used to measure the pitot pressure in the slot. Normalized pitot pressure distributions for the M246A8 case are shown in Fig. 12. A total of 441 points was measured on a regular grid with $x$ and $y$ spacing, as indicated by the tick marks in Fig. 12. Near the top of the slot, very large flow angles relative to the pitot probe stem are expected, and the pitot data should be considered very uncertain. This probably accounts for the lack of a discrete barrier shock in the data. Also, note that the pitot probe will sense nearly static pressure in regions of reverse flow. These results indicate two fairly extensive regions of flow separation in the slot, which severely reduce the effective flow area. The data do indicate, however, that the flow reattaches before exiting into the bleed plenum.

The pitot and static pressure data were combined to calculate the local Mach number distribution in the slot, using the appropriate isentropic relations ${ }^{19}$ with the ratio of specific heats specified as

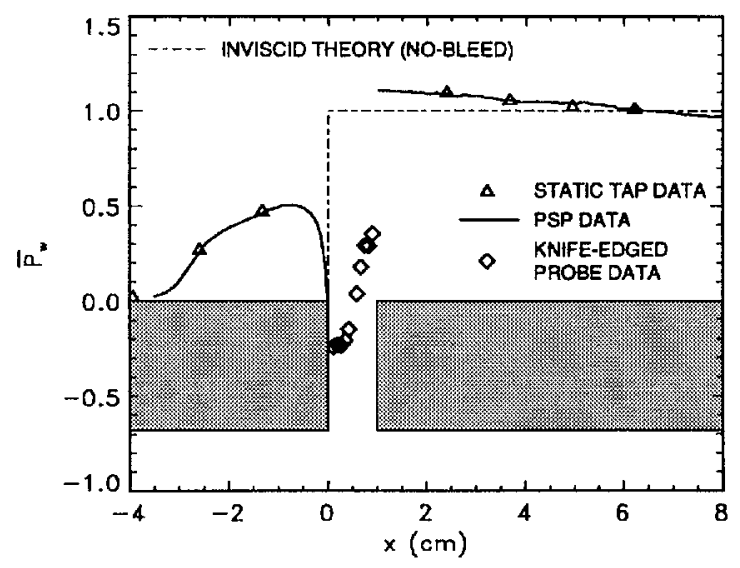

Fig. 10 Normalized static-pressure distribution along the $x$ axis, case M246A8, $\overline{\dot{m}}=6.38 \%$ 。 $\gamma=1.4$. For the calculation, the local static pressure $P$ data were interpolated onto the data grid used to acquire the pitot data. Recall that the static pressure at the slot surface was set equal to the first column of data and recognize that this may introduce errors in the Mach number values nearest the slot surface. The calculated Mach number distributions for the M198A6 and M246A8 cases are shown in Figs. 13 and 14, respectively. The presence of the separation region on the upper-left surface of the slot causes an aerodynamic convergent-divergent nozzle effect. As the flow expands downstream of the aerodynamic throat, the Mach number increases to a peak of about $M=2$ for both cases. The backpressure in the plenum, however, is not low enough to maintain supersonic flow. But rather than shocking down to subsonic flow, as would happen for the inviscid case, the plenum pressure feeds up through the boundary layer on the slot surface, which causes the flow to separate. Compression waves off of this separation act to decelerate the flow gradually but still the flow exits the slot supersonically. The upper separated region also leaves a rather large subsonic wake that accelerates to a near-sonic condition at the slot exit.

Following Coleman and Steele, ${ }^{20}$ the propagation of the bias and precision uncertainties in the measured pitot and static pressures into the calculated Mach number were estimated. The overall uncertainty in the Mach number $U_{M}$, is then estimated by root-sum squaring (95\% confidence) the bias and precision uncertainties. ${ }^{19}$ The overall uncertainty in the Mach number was evaluated at each point in the flowfield, and the results are shown in Fig. 15 as a function of the local Mach number. Note that this Mach number uncertainty includes only the propagation of pressure measurement uncertainty and not errors attributable to probe interference, misalignment, or interpolation. The results indicate that the uncertainty becomes excessive for a local Mach number less than 0.5 , which is confined to relatively small regions of the flowfield.

\section{Three-Dimensionality of the Flowfield}

From the surface static-pressure distributions (Figs. 7 and 8), we inferred that the mass-flow distribution in the spanwise $(z)$ direction was not uniform, but passed a higher mass flow at the center of the slot. If we assume that the total temperature of the flow in the slot is the same as that of the wind-tunnel plenum, then in conjunction with the static-pressure and Mach number distributions in the slot, and assuming that the ideal gas law applies, we can calculate a massflux $(-\rho V)$ distribution in the slot. Integrating the $-\rho V$ distribution along lines of constant $(y)$ locations and then dividing by the unit mass flow in the reference boundary layer yields a normalized mass flow in the plane of symmetry:

$$
\overline{\dot{m}}_{\mathrm{cl}}=100 \cdot \frac{\int_{0}^{D_{x}}-\rho V \mathrm{~d} x}{\dot{m}_{\mathrm{bl}, \mathrm{rcf}}^{\prime}}
$$

There are, however, at least three sources of errors to consider when performing the integration: regions of high flow angle relative to the pitot probe stem, regions of reverse flow, and regions where the static pressure has a high gradient near the wall, which makes our extrapolation assumption uncertain. The integrations were performed along 18 rows of data, and the results are shown in Fig. 16. In this plot, the centerline mass flow calculated from Eq. (4) is normalized by the bulk mass flow measured with the ASME nozzle and presented as a function of $-y$ location. Data near the top of the slot $\left(-y / D_{x}<0.3\right)$ are omitted because of the expected large flow angles relative to the pitot probe. From this figure we can estimate that for the bulk mass flows considered, on the average the centerline mass flow is roughly $50 \%$ higher than the bulk mass flow. Also, the increase in centerline mass flow through the slot indicates a significant spanwise convergence of the flow within the slot.

With regard to the cause of the observed three-dimensionality of the flowfield, there are three geometric considerations: the bleed plenum, the boundary-layer fences, and the end effects of the slot itself. The bleed plenum is unlikely to be contributing to the nonuniform flow inasmuch as the spanwise dimension of the plenum $(30 \mathrm{~cm})$ is nearly twice the span of the $\operatorname{slot}(16.5 \mathrm{~cm})$ and the depth of the plenum $(60 \mathrm{~cm})$ is approximately twice that of the span. More likely is that the nonuniform condition is attributable to a combination of the boundary-layer fences and slot end effects. Under 


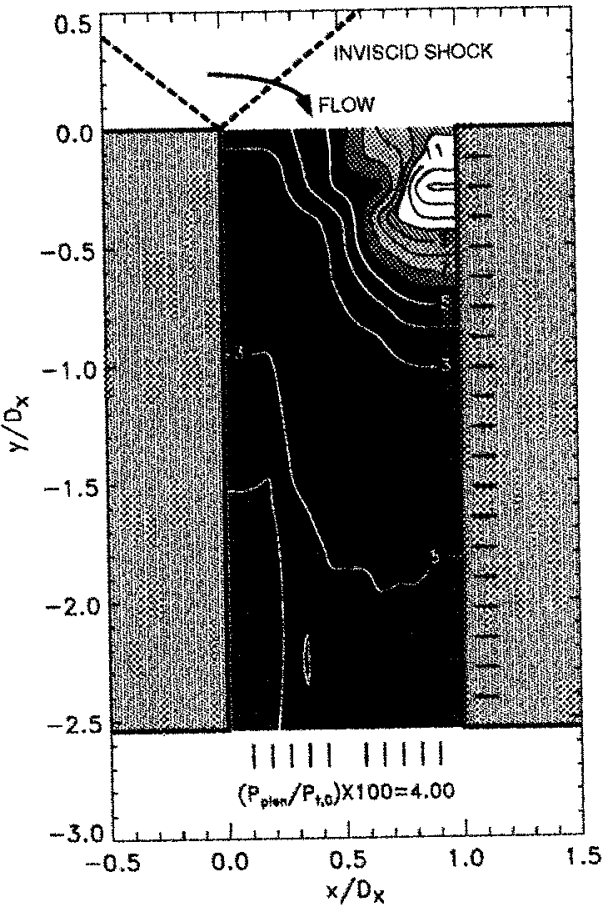

Fig. 11 Normalized static-pressure distribution $\left[\left(P / P_{t, 0}\right) \times 100\right]$, case M246A8, $\overline{\dot{m}}=6.38 \%$.

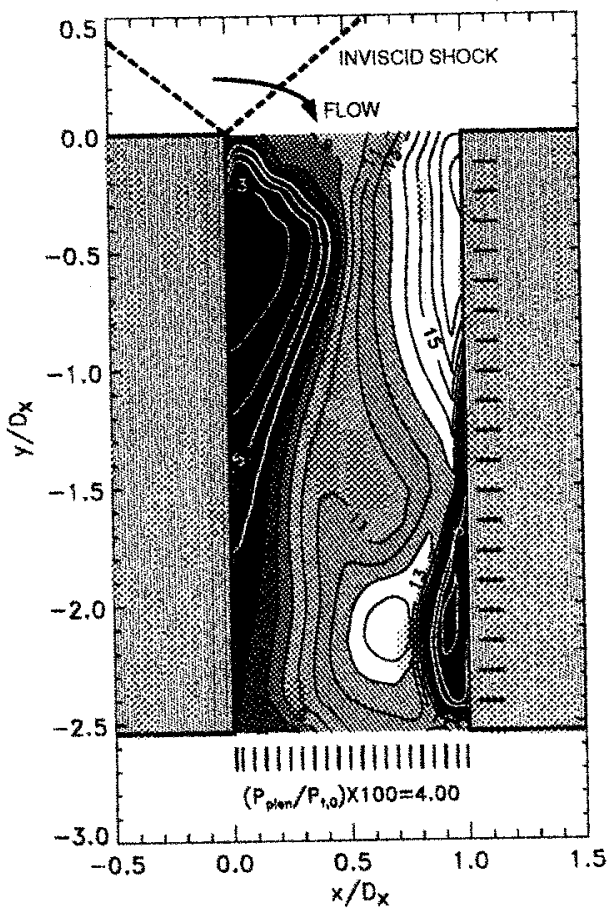

Fig. 12 Normalized pitot pressure distribution $\left[\left(P_{t 2} / P_{t, 0}\right) \times 100\right]$, case M246A8, $\overline{\dot{m}}=6.38 \%$.

no-bleed conditions, the oblique shock wave separates the windtunnel boundary layer nearly uniformly across most of the span of the wind-tunnel wall. The fence corner region, however, is more susceptible to separation because of the low momentum of the fluid in the corner. In addition, the glancing shock wave and boundarylayer interaction on the fence surface causes the flow separation to extend up the side of the fence. The result of the corner interaction is to locally turn the flow toward the wind-tunnel centerline. Removing the fences is not an option, however, because previous experience has shown that the separation of the much thicker windtunnel corner boundary layer prevents spanwise uniformity for all bleed conditions, zero or otherwise. When bleed is applied to the

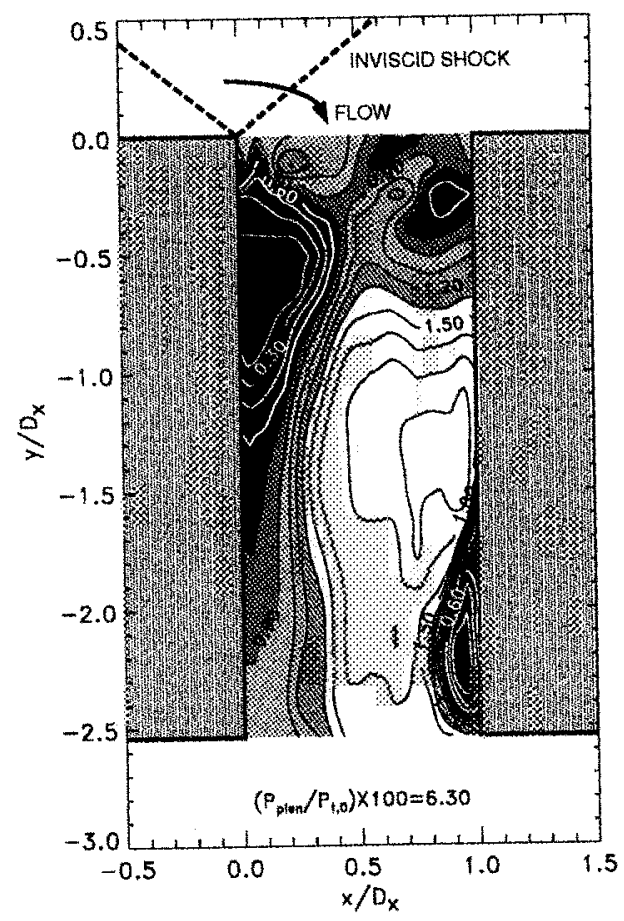

Fig. 13 Calculated Mach number distribution, case M198A6, $\overline{\dot{m}}=$ $7.63 \%$.

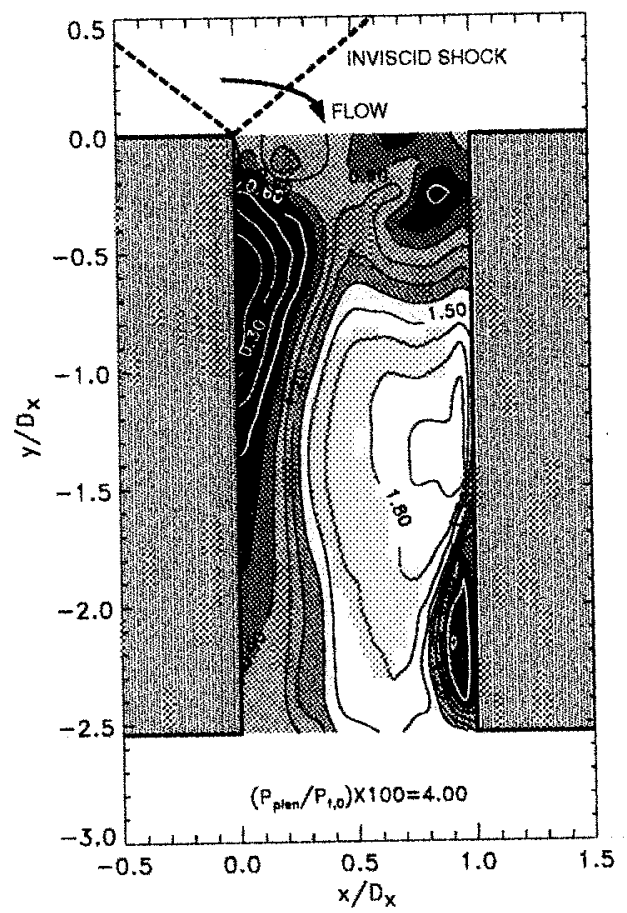

Fig. 14 Calculated Mach number distribution, case M246A8, $\ddot{\dot{m}}=$ $6.38 \%$.

fenced configuration, the separation in the vicinity of the fence corner is not affected by the bleed as much as at the centerline because the slot does not extend all the way to the fence. The result is that the nominally two-dimensional no-bleed separation becomes threedimensional, significantly affecting the local bleed flow rate through the slot. The above conjectured behavior has been supported by surface oil fiow visualization, which shows very large flow angles $(\sim 45$ deg) converging toward the centerline in the vicinity of the corners under bleed and no-bleed conditions. However, further experimental data in conjunction with CFD analysis likely will be required to fully understand this complex interaction. Extending the slot fully to the corner and perhaps increasing the slot area locally in the 


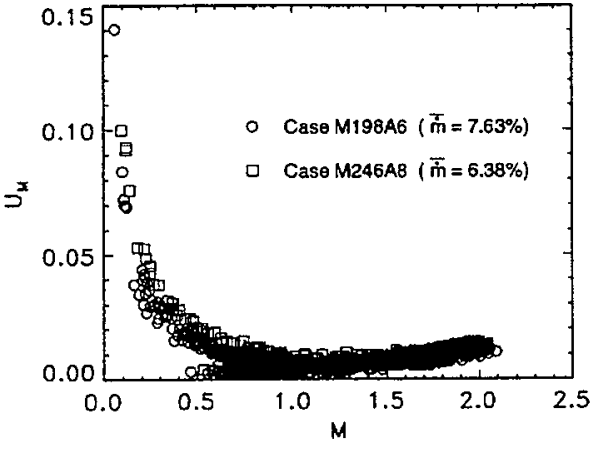

Fig. 15 Uncertainty in Mach number vs Mach number.

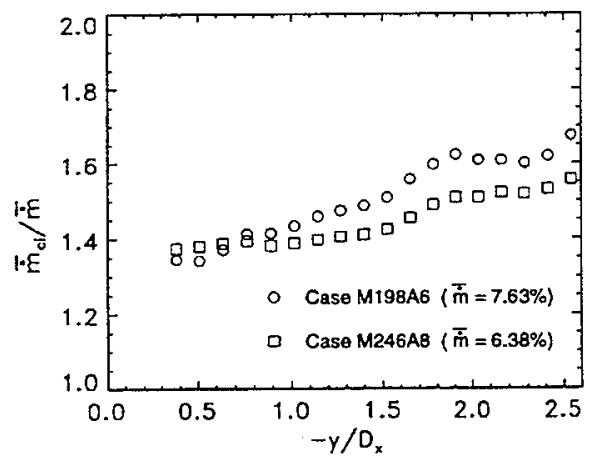

Fig. 16 Integrated mass flow in the plane of symmetry.

corner may alleviate the problem and will be the subject of a future investigation.

\section{Concluding Remarks}

Development of global bleed models for boundary-layer control will require experimental and computational synergism because of the complexity of the flowfield. The flowfield inside a bleed slot used to control an oblique shock-wave and turbulent boundary-layer interaction has been studied experimentally. From this study we can draw the following conclusions:

1) For the configuration tested, despite a nominally twodimensional fowfield for the zero-bleed case, application of bleed flow resulted in a highly three-dimensional flowfield. Surface staticpressure data and local mass-flow calculations indicate that the slot passes significantly more mass flow near the center than at the ends. This may very well be the case in actual inlet bleed systems.

2) The flowfield in the plane of symmetry of the slot is characterized by the presence of a barrier shock and two large separation regions. These features serve to reduce the flow coefficient of the bleed passage, and their effects should be included in flow coefficient models.

3) Because of an aerodynamic throat effect of the separation, much of the flow through the slot is supersonic.

\section{Acknowledgment}

The authors would like to gratefully acknowledge $\mathrm{T}$. Bencic of NASA Lewis Research Center for matters concerning the pressuresensitive paint technique.

\section{References}

${ }^{1}$ Delery, J. M., "Shock-Wave/Turbulent Boundary-Layer Interaction and Its Control," Progress in Aerospace Sciences, Vol. 22, No. 4, 1985, pp. 209 280.

${ }^{2}$ Hamed, A., and Shang, J., "Survey of Validation Data Base for ShockWave/Boundary-Layer Interactions in Supersonic Inlets," Journal of Propulsion and Power, Vol. 7, No. 4, 1991, pp. 617-625.

${ }^{3}$ Hamed, A., and Lehnig, T., "An Investigation of Oblique Shock/ Boundary-Layer/Bleed Interaction," Journal of Propulsion and Power, Vol. 8, No. 2, 1992, pp. 418-424.

${ }^{4} \mathrm{Hamed}$, A., Shih, S., and Yeuan, J. J., "A Parametric Study of Bleed in Shock/Boundary-Layer Interactions," AIAA Paper 93-0294, Jan. 1993.

${ }^{5}$ Hamed, A., Yeuan, J. J., and Shih, S., "An Investigation of Shock Wave/Turbulent Boundary-Layer Interaction with Bleed Through Normal and Slanted Holes," AIAA Paper 93-2 I55, June 1993.

${ }^{6}$ Hamed, A., Yeuan, J. J., and Shih, S., "Flow Characteristics in Boundary-Layer Bleed Slots with Plenum," AIAA Paper 95-0033, Jan. 1995

${ }^{7}$ Hamed, A., Yeuan, J. J., and Shih, S., "An Investigation of Shock Wave/Turbulent Boundary-Layer Interaction with Bleed Through Slanted Slots," AIAA Paper 93-2992, July 1993.

${ }^{8}$ Hahn, T. O., Shih, T. I.-P., and Chyu, W. J., "Numerical Study of ShockWave/Boundary-Layer Interactions with Bleed," AIAA Journal, Vol. 31, No. 5, 1993, pp. 869-876

${ }^{9}$ Rimlinger, M. J., Shih, T. I.-P., and Chyu, W. J., "Three-Dimensional Shock-Wave/Boundary-Layer Interactions with Bleed Through a Circular Hole," AIAA Paper 92-3084, July 1992.

${ }^{10}$ Chyu, W. J. Rimlinger, M. J., and Shih. T. I.-P., "Effects of BleedHole Geometry and Plenum Pressure on Three-Dimensional ShockWave/Boundary-Layer/Bleed Interactions," AIAA Paper 93-3259, July 1993.

${ }^{11}$ Shih, T. I.-P., Rimlinger, M. J., and Chyu, W. J., "Three-Dimensional Shock-Wave/Boundary-Layer Interactions with Bleed," AIAA Journal, Vol. 31, No. 10, 1993, pp. 1819-1826.

${ }^{12}$ Rimlinger, M. J., Shih, T. I.-P., and Chyu, W. J., "Three-Dimensional Shock-Wave/Boundary-Layer Interactions with Bleed Through Multiple Holes," AIAA Paper 94-0313, Jan. 1994

${ }^{13}$ Harloff, G. J., and Smith, G. E., "On Supersonic-Inlet Boundary-Layer Bleed Flow," AIAA Paper 95-0038, Jan. 1995.

${ }^{14}$ Porro, A. R., and Hingst, W. R., "Use of Surface Heat Transfer Measurements as a Flow Separation Diagnostic in a Two-Dimensional Reflected Oblique Shock/Turbulent Boundary-Layer Interaction," AIAA Paper 930775, Jan. 1993.

${ }^{15}$ Blumenthal, P. Z., "A PC Program for Estimating Measurement Uncertainty for Aeronautics Test Instrumentation," AIAA Paper 95-3072, July 1995.

${ }^{16}$ Bencic, T., "Experiences Using Pressure Sensitive Paint in NASA Lewis Research Center Propulsion Test Facilities," AIAA Paper 95-2831, July 1995.

${ }^{17}$ Bryer, D. W., and Pankhurst, R. C., Pressure-Probe Methods for Determining Wind Speed and Flow Direction, Her Majesty's Stationery Office, London, 1971, Chap. 2.

${ }^{18}$ Willis, B. P., Davis, D. O., and Hingst, W. R., "Flow Coefficient Behavior for Boundary-Layer Bleed Holes and Slots," AIAA Paper 95-0031, Jan. 1995.

${ }^{19}$ Davis, D. O., Willis, B. P., and Hingst, W. R., "Flowfield Measurements in a Slot-Bled Oblique Shock-Wave and Turbulent Boundary-Layer Interaction," AIAA Paper 95-0032, Jan. 1995.

${ }^{20}$ Coleman, H. W., and Steele, W. G., Experimentation and Uncertainty Analysis for Engineers, Wiley, New York, 1989, Chap. 4. 
